This item was submitted to Loughborough's Research Repository by the author.

Items in Figshare are protected by copyright, with all rights reserved, unless otherwise indicated.

\title{
Protection of steel in concrete using galvanic and hybrid electrochemical treatments
}

PLEASE CITE THE PUBLISHED VERSION

http://www.routledge.com/books/details/9780415899529/

PUBLISHER

CRC Press (@ Taylor and Francis)

VERSION

AM (Accepted Manuscript)

LICENCE

CC BY-NC-ND 4.0

REPOSITORY RECORD

Glass, Gareth K., Christian Christodoulou, and S.P. Holmes. 2019. "Protection of Steel in Concrete Using Galvanic and Hybrid Electrochemical Treatments". figshare. https://hdl.handle.net/2134/10948. 
This item was submitted to Loughborough's Institutional Repository (https://dspace.lboro.ac.uk/) by the author and is made available under the following Creative Commons Licence conditions.

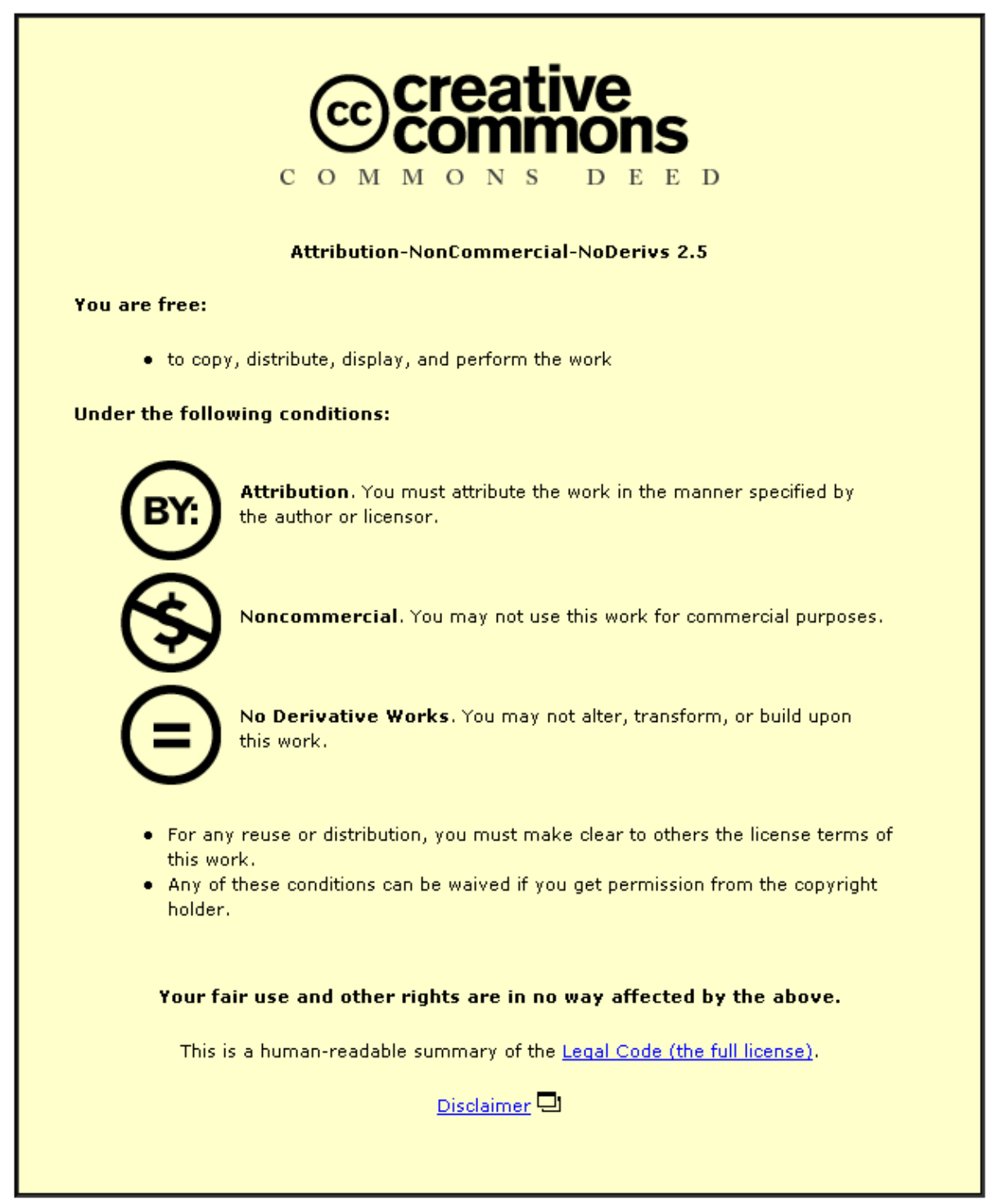

For the full text of this licence, please go to: http://creativecommons.org/licenses/by-nc-nd/2.5/ 


\title{
Protection of Steel in Concrete Using Galvanic and Hybrid Electrochemical Treatments.
}

\author{
G.K. Glass \\ Concrete Preservation Technologies, Nottingham, UK \\ Christian Christodoulou \\ AECOM, Birmingham, UK \\ Steven Holmes 1 \\ Concrete Preservation Technologies, Nottingham, UK
}

\begin{abstract}
In this study, data from galvanic and hybrid electrochemical treatments applied to structures is analysed. It is shown that the protection of steel in concrete using galvanic anodes finds theoretical support from a basis of improving the environment or maintaining a benign environment at the steel. Protection current output responds to the aggressive nature of the environment and, as a result, galvanic anodes have substantially longer lives than originally predicted. Monitoring is preferably focused on monitoring the effect of the protection on the condition of the structure and may be achieved by monitoring either steel corrosion rate and/or steel corrosion potential. Monitoring is preferably combined with a risk management option such as a facility to apply a temporary impressed current treatment to arrest active corrosion if a risk is identified. An allowance for new galvanic protection criteria has been made in the latest European standard on Cathodic Protection of Steel in Concrete.
\end{abstract}

\section{INTRODUCTION}

Corrosion of steel in concrete is an electrochemical process and electrochemical techniques have been used to control corrosion. The simplest of these techniques is galvanic protection. In this case a galvanic anode is connected to the steel and the anode corrodes while delivering a protection current to the steel. Another technique is a hybrid treatment in which a high protection current is briefly impressed off a galvanic anode before galvanic protection is applied (Holmes et al. 2011a). This work looks at data from such systems and considers their performance.

\section{RESULTS}

\subsection{Galvanic Anodes}

Galvanic anodes were installed at the edge of patch repairs on a car park deck suffering from deicing salt induced corrosion. Figure 1 shows an aspect of the installation process. The anodes were installed in drilled holes $(25 \mathrm{~mm}$ diameter by $40 \mathrm{~mm}$ deep) in the parent concrete and were encapsulated in a proprietary putty and connected to the steel.

Figures 2 - 3 shows the potential changes relative to an arbitrary reference at some distance from the edge of the patch repairs where the anodes were considered to have no influence on the potentials (Christodoulou et al. 2011).

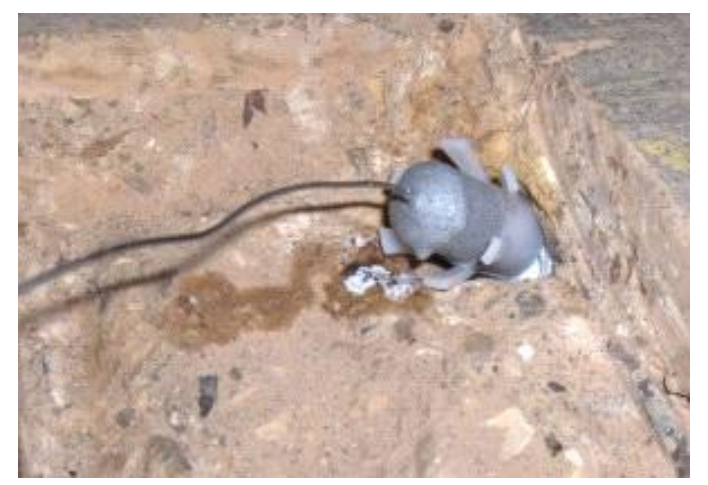

Figure 1 Installation of a galvanic anode at an area of concrete repair.

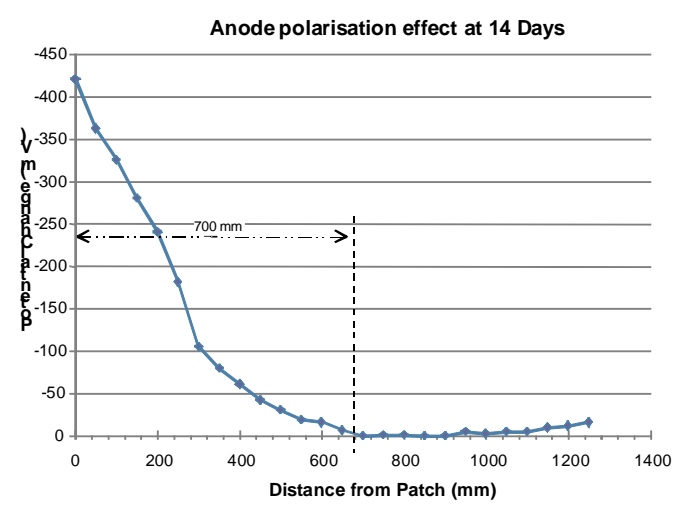

Figure 2 Change in potential induced by anodes installed in concrete repairs. 


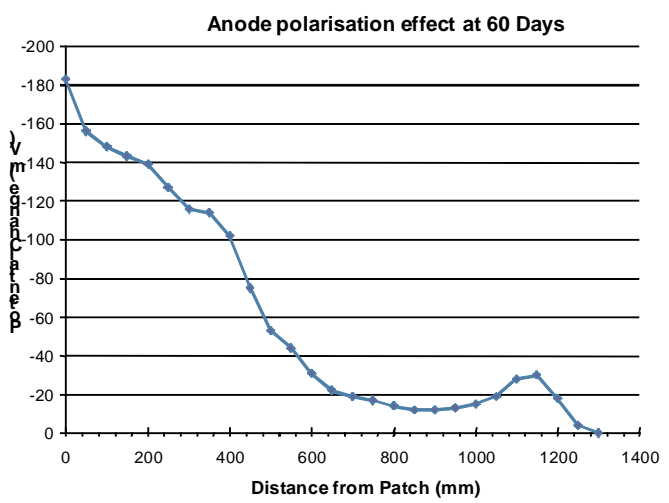

Figure 3 Change in potential induced by anodes installed in concrete repairs.

Potential measurements were taken at both 14 and 60 days. The locations did not coincide because access was limited by parked cars. The data shows that in both cases, the anodes had a dominant influence on the potential changes to a distance of about $600 \mathrm{~mm}$.

\subsection{Hybrid treatments.}

A hybrid treatment briefly impresses a high current off a galvanic anode using a battery or temporary power supply for a period of about a week to arrest active corrosion before connecting the anode to the steel to continue delivering galvanic protection. A Hybrid Anode ${ }^{\mathrm{TM}}$ consisting of a discrete galvanic anode with an impressed current connection is generally used. Figure 4 shows an example of such an anode temporarily fitted in a drilled hole with a titanium connection detail.

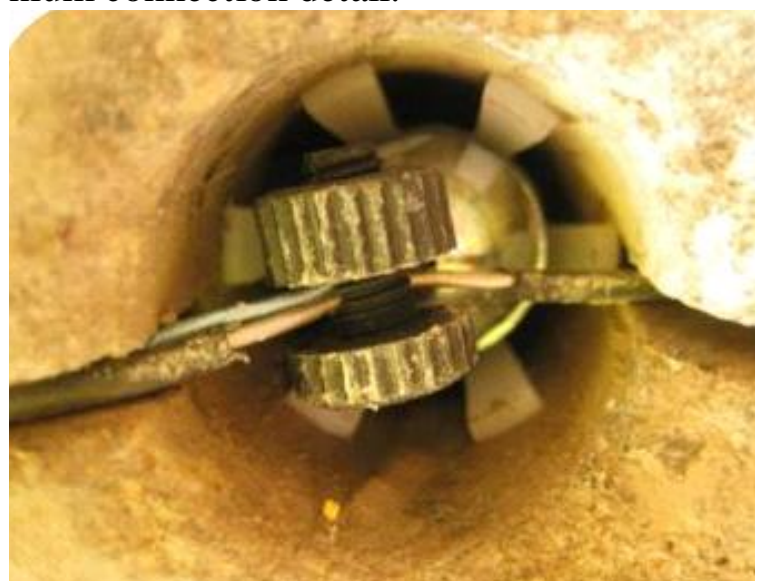

Figure 4 A galvanic anode with a titanium connection temporarily fitted in a hole.

Data was collected from hybrid treatments applied to bridge piers and abutments suffering from chloride induced corrosion. Figure 5 shows the effect of the treatment on open circuit steel potentials (Holmes et al. 2011b). The steel potential shifted to much more positive values after 60 days of protection in this example.

Figures 6 - 8 shows the logged currents, temperature and potentials obtain on a bridge structure over a 4 year period. The current output was subject to daily and seasonal fluctuations arising from changes in the temperature with higher temperatures resulting in more current. Flooding occurred after 530 and 840 days and this again caused the current output to increase and the potentials to fall.

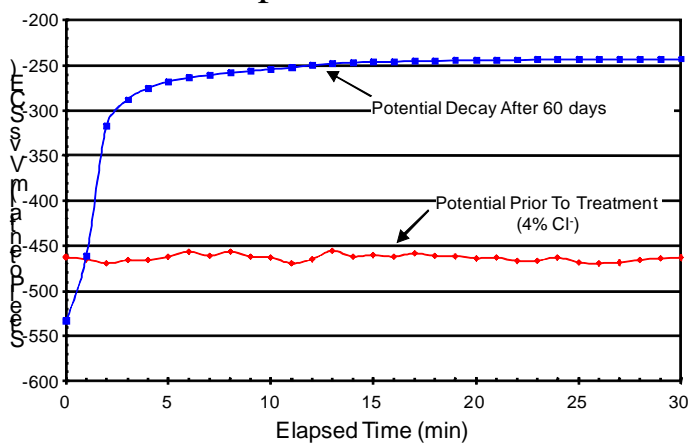

Figure 5 Effect of hybrid galvanic anode treatment on steel potentials.

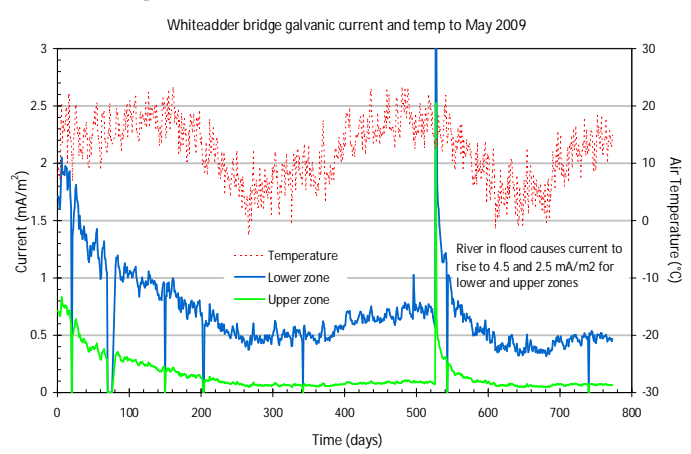

Figure 6 Protection current, steel potential and temperature from a bridge structure.

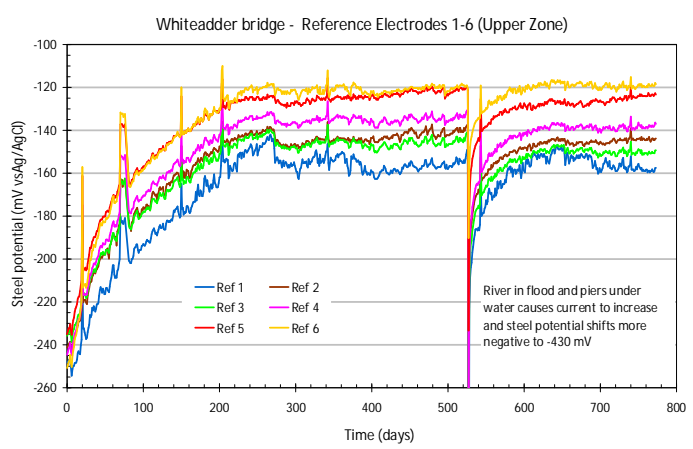

Figure 7 Steel potentials from a bridge structure.

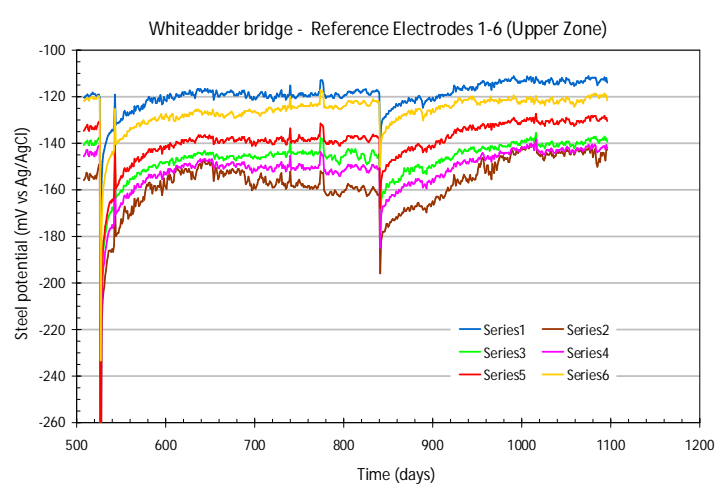

Figure 8 Steel potentials from a bridge structure.

Figure 9 shows an example of steel potentials and corrosion rates obtained on a bridge subject to hybrid galvanic anode treatment (Glass et al. 2008). The potentials shifted to more positive values over the first two years of operation while the corrosion rates were all below $1 \mathrm{~mA} / \mathrm{m}^{2}$. 


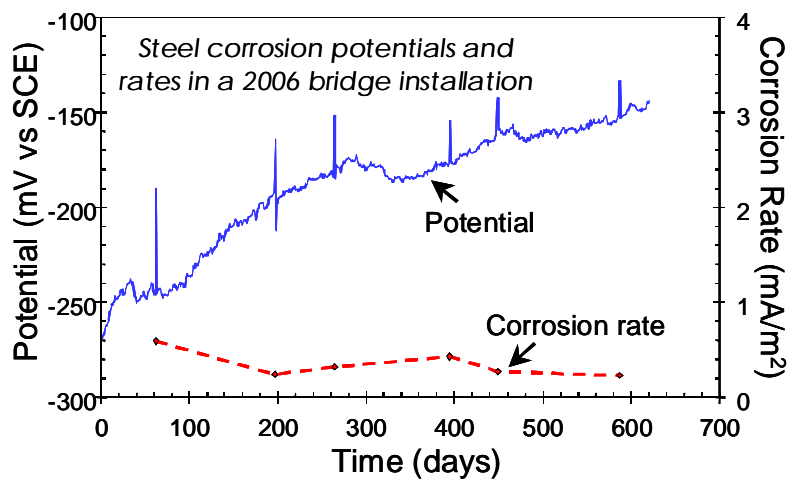

Figure 9 Steel potentials and corrosion rated from protected bridge elements.

\section{DISCUSSION}

\subsection{Basis for Galvanic protection.}

The protective effects of electrochemical treatments are broadly described as chloride extraction, re-alkalisation and a negative steel potential shift. These are summarised in Table 1 and tend to be related to different electrochemical treatments (Mietz 1998). However all mechanisms operate in any continuous treatment.

\begin{tabular}{l|c|c|c} 
& $\begin{array}{c}\text { Re- } \\
\text { Alkalisation } \\
\text { (CEN.TS } \\
\mathbf{1 4 0 3 8 - 1 )}\end{array}$ & $\begin{array}{c}\text { Chloride Ex- } \\
\text { traction } \\
\text { (prCEN.TS } \\
\mathbf{1 4 0 3 8 - 2})\end{array}$ & $\begin{array}{c}\text { Cathodic Pro- } \\
\text { tection } \\
\text { (EN } \\
\mathbf{1 2 6 9 6 : 2 0 1 2})\end{array}$ \\
\hline $\begin{array}{l}\text { Protection } \\
\text { objective }\end{array}$ & $\begin{array}{c}\text { Passivating } \\
\text { environment } \\
\text { (restore high } \\
\text { pH) }\end{array}$ & $\begin{array}{c}\text { Passivating en- } \\
\text { vironment (re- } \\
\text { move chloride) }\end{array}$ & $\begin{array}{c}\text { Potential } \\
\text { (adequate pola- } \\
\text { risation) }\end{array}$ \\
\hline $\begin{array}{l}\text { Treatment } \\
\text { Time }\end{array}$ & $\begin{array}{c}\text { Temporary } \\
(3-14 \text { days) }\end{array}$ & $\begin{array}{c}\text { Temporary } \\
(6-10 \text { weeks) }\end{array}$ & Permanent \\
\hline $\begin{array}{l}\text { Current } \\
\text { Density }\end{array}$ & $0.8-2 \mathrm{~A} / \mathrm{m}^{2}$ & $0.8-2 \mathrm{~A} / \mathrm{m}^{2}$ & $3-20 \mathrm{~mA} / \mathrm{m}^{2}$
\end{tabular}

Table 1 Summary of protective effects and associated treatments.

Both carbonation and chloride induced corrosion damage result from a reduction in the $\mathrm{pH}$ at the steel. In the case of chloride induced corrosion this reduction in $\mathrm{pH}$ is localised. Chloride induced corrosion is sometimes termed autocatalytic (self-accelerating) (Glass et al. 2008). A pit nucleation event at the site of corrosion initiation leads to the formation of soluble iron ions. These react with water to produce iron hydroxide and positive hydrogen ions. Chloride ions act as a charge balancing species. Hydrochloric acid is effectively produced. Corrosion propagates because a macro-corrosion cell is formed. The generation of acid at a corroding site is balanced by the generation of hydroxide away from the corroding site.
The dominant effect in the cases of continuous electrochemical treatments is most probably an improvement in the environment at the steel (Christodoulou et al. 2010). The evidence for this comes from the long time required to achieve protection and the low protection current densities relative to the localised steel corrosion rate at which protection is achieved (Glass et al. 2008). Much less current is required to prevent corrosion initiation than that required to arrest an existing corrosion process.

Specific evidence from galvanic systems come from the observation that zinc, thermally applied to concrete surfaces does give adequate protection in aggressive subtropical marine conditions. If it can protect steel in aggressive conditions, then it should also be able to protect steel in less aggressive conditions (Holmes et al. 2011a).

Galvanic current output tends to fall with time as the anode is consumed (Fig. 6). As a result galvanic protection is not generally achieved by sustaining an adequate level of steel polarisation. Indeed some galvanic anode systems are only installed as a corrosion prevention system and rely on concrete patch repairs to arrest active corrosion.

\subsection{Responsive Behaviour.}

Galvanic protection does not have a user controllable protection current output. However the protection current output of a galvanic anode varies with temperature and moisture content in the same way that the corrosion rate of steel varies with these factors. This is termed responsive behaviour. As shown in Figures 6 to 8 current from galvanic anodes increases in wet an hot environment which are also more aggressive to steel.

In cold and dry periods, the current output falls. As a result the life of the anode is increased. The service life of an anode is not determined by a maximum current density, but by a much lower average current density (Holmes et al. 2011a).

\subsection{Monitoring.}

Monitoring the performance of galvanic anodes is preferably focused on monitoring changes in the condition of the structure that arise as the result of the protection because galvanic protection does not generally sustain high levels of steel polarisation. Examples include corrosion potential as a function of time and/or distance from an anode or edge of the repaired area and/or corrosion rate (Christodoulou et al. 2011).

Figure 5 provides an example of how the open circuit steel potential shifted to substantially more passive (positive) values after a period of protection. Figure 2 provides an example of the effect of the anodes on the change in potential in the concrete near the edge of a concrete repair area. Figure 9 provides 
an example of how the corrosion rate changed with an increasing period of treatment.

Corrosion rates up to $2 \mathrm{~mA} / \mathrm{m}^{2}$ are generally considered to be very low or passive. An acceptance criteria might include demonstrating that the corrosion rate at a selected locations representing areas of high corrosion risk is less than $2 \mathrm{~mA} / \mathrm{m}^{2}$. Such a criterion is suited to a treatment primarily aimed at arresting existing active corrosion such as the hybrid electrochemical treatment described above [4].

Some galvanic protection methods are aimed at preventing incipient anodes from forming. In this case the treatment is preventative. One acceptance criterion in this case is to measure the effect of the anodes on the potential through the concrete along a line extending away from the edge of a repaired area and to show that the influence of the anodes dominates the potential changes to a distance of $300 \mathrm{~mm}$.

\subsection{Acceptance of Galvanic Technology.}

The use of galvanic anodes to provide protection has recently been added to the European Standard on Cathodic Protection of Reinforced Concrete (BS EN 12696:2012). Criteria such as those suggested above are allowed for galvanic anodes.

Monitoring is preferably combined with a risk management option in the event that monitoring shows evidence of active corrosion. This is a requirement imposed by the revised European Standard. Such an option could be to include a facility to apply a temporary impressed current treatment to arrest active corrosion if active corrosion is identified.

One advantage of the technique is it is much less complex than other electrochemical techniques and improvements have been made (e.g. the hybrid anode system described above) to overcome the limited power in galvanic anodes. Thus the number and variety of case histories is growing rapidly.

\section{CONCLUSIONS}

The protection of steel in concrete using galvanic anodes finds theoretical support from a basis of protecting the steel by improving the environment or maintaining a benign environment at the steel. Galvanic protection is not generally achieved by sustaining an adequate level of steel polarisation.

Protection current output responds to the aggressive nature of the environment and as a result galvanic anodes have substantially longer lives than originally predicted because the anode is not consumed in cold and dry conditions.

Monitoring the performance of galvanic anodes is preferably focused on monitoring the effect of the protection on the condition of the structure and may be achieved by monitoring either steel corrosion rate and/or steel corrosion potential. Monitoring is pref- erably combined with a risk management option such as a facility to apply a temporary impressed current treatment to arrest active corrosion if a risk is identified.

Galvanic protection is increasingly being used because it is less complex than other electrochemical techniques. There are now a significant number and variety of case histories of galvanic and hybrid applications. An allowance for new galvanic protection criteria has been made in the latest European standard on Cathodic Protection of Steel in Concrete.

\section{REFERENCES}

Christodoulou, C., Glass, G., Webb, J., Austin, S. and Goodier C., "Assessing the long term benefits of Impressed Current Cathodic Protection" Corrosion Science 52 (2010) p. 2671-2679.

Christodoulou C., Glass G., Webb J., Austin S. and Goodier C., 2011, "A new approach for the patch repair of car parks using galvanic anodes", Concrete Solutions 4th International Conference on Concrete Repair, 26-28 September 2011, Dresden.

Glass, G.K., Roberts, A.C., Davison, N., "Hybrid corrosion protection for chloride contaminated concrete" Proceedings of the Institute of Civil Engineers, Construction Materials, 161 (2008) p. 163-172.

Holmes S.P., Wilcox G.D., Robins P.J., Glass G.K. and Roberts A.C., 2011a "Responsive behaviour of galvanic anodes in concrete and the basis for its utilisation" Corrosion Science 53 p. $3450-3454$.

Holmes S.P., Wilcox G.D., Robins P.J., Glass G.K. and Roberts A.C., 2011b "Long term assessment of a hybrid electrochemical treatment", Materials and Corrosion 62, p. 1-7.

Mietz J. 1998, Electrochemical Rehabilitation Methods for Reinforced concrete Structures, A state of the Art Report, European Federation of Corrosion publication number 24, p.1. 